\title{
Neonatal Resuscitation Capacity Building and Research on its Impact: Need of the Hour!
}

\author{
AKASH BANG \\ From the Department of Pediatrics, Mahatma Gandhi Institute of Medical Sciences, \\ Sewagram, Maharashtra, India.drakashbang@gmail.com
}

$\mathrm{T}$ he measure of a civilization is how it treats its weakest members," said Mahatma Gandhi. Newborns are undisputedly the weakest members of our society. Globally, neonatal deaths now account for over $40 \%$ of the under- 5 deaths, and must be addressed to accelerate progress towards the Sustainable Development Goal - 3 (SDG3), since reducing the neonatal mortality to 12 per 1000 livebirths by 2030 is one of the targets under SDG3 [1]. India is the epicentre of world's neonatal mortality with every fourth dying newborn of the world being Indian [1,2]. Close to 700,000 newborns die every year in India - a horrifying rate of 2 neonatal deaths every minute [2]. Preterm birth complications (34\%), infections ( $21 \%$ ), and birth asphyxia (24\%) are the three topmost causes of neonatal mortality worldwide [1]. Mortality risk is highest on the first day of life contributing upto $36 \%$ of all neonatal deaths - most of these due to birth asphyxia [1].

Apart from neonatal deaths, two worrisome aspects are very closely linked to birth asphyxia. First, many health facilities do not keep detailed records of fresh still births (FSB). National still birth estimates suggest that around 600,000 still births occur every year in India [3]. Of these, $30 \%$ are attributed to the intra-partum causes, mostly birth asphyxia. However, due to various social, legal and moral pressures and stigma surrounding a neonatal death, misclassifications of neonatal deaths as FSBs are common whether deliberately or unknowingly. Thus, the real asphyxia-related mortality includes many unreported still births, and thus far exceeds the reported numbers. Second, mortality is just a small 'tip of the iceberg' of the impact of birth asphyxia. Worldwide more than one million children surviving birth asphyxia annually go onto suffer its long-term consequences cerebral palsy, learning disorders and other disabilities [4].

On the brighter side, birth asphyxia operates mainly in the first few minutes immediately after birth, and hence, unlike the other two causes, provides a narrow but definite window of opportunity. If appropriate actions are taken in this narrow timeframe - essentially the First Golden Minute of life - a big load of neonatal mortality is largely preventable. For this, it is crucial whoever is likely to attend a birth in the capacity of a health personnel, needs to be identified and trained in these steps of basic neonatal resuscitation - preparation for birth; newborn assessment at birth to identify whether it is breathing well on its own or needs assistance; initial steps viz. providing warmth, clearing airway as necessary, thorough drying, and stimulation to start breathing; and positive pressure ventilation by bag and mask, if needed. These simple steps can be learnt by any healthcare personnel, and are sufficient to manage almost $99 \%$ of newborns as advanced resuscitative measures like chest compression and medications are known to be required in hardly $1 \%$ of the births [5]

'Helping Babies Breathe (HBB)' by the American Academy of Pediatrics (AAP) is a simple, evidence-based training curriculum in basic newborn resuscitation for birth attendants [6]. The Indian Academy of Pediatrics (IAP) and the Government of India have prepared a similar basic resuscitation training program called Navjaat Shishu Suraksha Karyakram' in government and 'Basic Neonatal Care and Resuscitation Program' in private sector. The Neonatal Resuscitation Program - First Golden Minute (NRP-FGM) Project of IAP aims to train 200,000 birth attendants through a network of trainers from its own members and partner organizations [7].

Studies have evaluated the impact of training of physicians, nurses and other birth attendants in neonatal care and resuscitation, and clearly demonstrated a dramatic increase in their skills and knowledge [8]. However, the impact on perinatal outcomes has understandably been less dramatic at the best, and variable at the worst [9-11]. The Eunice Kennedy Shriver National Institute of Child Health and Human Development (NICHD) Global Network (GN) for Women's and Children's Health Research recently conducted a multicentric pre-post study (GN-HBB study) in one Kenyan and two Indian sites, and did not find any effect 
of HBB implementation in selected health facilities on day-7 perinatal mortality in the communities served by the trained facilities, possibly because only $42-45 \%$ of the women in the 3 sites delivered in these facilities [12]. On the other hand, a recent meta-analysis of 2 randomized trials and 18 pre-post studies concluded that neonatal resuscitation trainings resulted in significant reduction in stillbirths and early neonatal mortality [13].

In this issue of Indian Pediatrics, Das, et al. [14] have reported the impact of neonatal resuscitation capacity building of birth attendants at district and sub-district level facilities in three high mortality districts of Uttar Pradesh, India, on fresh still births (FSBs). In addition to the training in essential newborn care and resuscitation, their intervention package also included establishing skill laboratories, ensuring availability of resuscitation equipments, and improved documentation, monitoring and supervision. The investigators very appropriately used a rigorous three-day training module with the AAPrecommended 1:6 trainer:trainee ratio, enhanced emphasis on skill building, and external monitors for ensuring quality and uniformity. They backed these trainings with additional trainings for staff turnover, and a host of monitoring activities. The GN-HBB study had used similar rigorous training and monitoring and showed that HBB training significantly improved neonatal resuscitation knowledge and skills [8]. However, over time, the skills declined more than knowledge and the study recommended that ongoing skills practice and monitoring, more frequent retesting, and refresher trainings are needed to maintain neonatal resuscitation skills. Though, Das, et al. [14] mention that four skill laboratories were established in each district, it would have been helpful if they also had specified their recommended frequency of practice and the actual extent of compliance, especially since practice frequency seems to be closely linked with skill retention.

Das, et al. [14] have compared FSB rates pre- and post-intervention, and report a pooled reduction of $0.5 \%$ (from $3.2 \%$ of all deliveries in pre- to $2.7 \%$ in post-period) across all sites. The risk of FSB in a pregnancy was $10 \%$ less in post-period (RR $0.90 ; 95 \%$ CI 0.88 to 0.92 ). This by itself is quite encouraging as the study was conducted in low resource settings of public health facilities where neonatal mortality was high. It also supports the hypothesis that FSBs can sometimes be misclassified neonatal deaths, and hence can be reduced with the interventions aimed at reducing neonatal mortality. However, this optimistic conclusion also has some caveats that must be kept in mind in addition to other limitations already discussed by the authors. First, for the same reason of possible misclassification between FSB and early neonatal deaths, any conclusion about resuscitation-related outcomes will be incomplete and misguided unless we also look at neonatal mortality simultaneously. If the reduction in FSB was associated with an equivalent rise in neonatal deaths, it may just mean re-categorization due to improved definitions or awareness. Hence, it is imperative to see simultaneous data on neonatal mortality or at least first day newborn deaths. Second, though the authors have mentioned that the profiles of deliveries in pre- and post-periods were comparable, it would be great if a table comparing the profile showed what parameters were compared and how the numbers stood. The authors also claim an improvement in resuscitation efforts at birth, but it would help if they shared data to back it. Third, as explained even by the authors, the three districts had high baseline infant and neonatal mortality. It is intuitive that any such intervention should work very well when the baseline is quite bad. The results may not be so easily generalized to districts or birthing units where the mortality rates are already low.

To conclude, this study by Das, et al. [14] asks an important and relevant research question, and opens up a lot of possibilities and opportunities as it was done in low resource settings of public facilities as close as it can get to the real field scenario. In future, we need more research on the frequency of skills-practice, refresher trainings, and various factors associated with loss of skills. Also, the outcomes selected need to be more holistic and translatable and relatable to the real-life situations. Future research should also focus on the threshold of neonatal mortality below which resuscitation trainings may not give significant results. The last and the biggest piece in the puzzle would be to carefully evaluate whether similar encouraging results will be seen outside of the research environment, and what it needs to sustain the results when the research funding is slowly withdrawn and there is drying up of the additional human resources, equipment and focussed motivation that come with a funded research study.

While we await further evidence, the only way forward towards SDG3 is conducting neonatal resuscitation trainings of rigorous quality that are focussed on skill acquisition; coupling them with monitoring and supervision activities aimed at long-term skill retention; and taking them to the lowest ranks of healthcare providers to ensure that every birth attendant is thorough with the basic resuscitation skills required to save the lives and prevent neurological damage in $99 \%$ of newborns. In settings where neonatal resuscitation was traditionally considered the domain of pediatricians and neonatologists, basic neonatal resuscitation training is a 
concept revolution, a huge empowerment of birth attendants, equipping them with the skills required for the most basic purpose of existence of the medical profession - saving lives!

Funding: None; Conflict of interest: None stated.

\section{REFERENCES}

1. Lawn JE, Blencowe H, Oza S, You D, Lee AC, Waiswa P, et al. Every Newborn: progress, priorities, and potential beyond survival. Lancet. 2014;384:189-205.

2. Million Death Study Collaborators. Changes in causespecific neonatal and 1-59-month child mortality in India from 2000 to 2015: a nationally representative survey. Lancet. 2017;390:1972-80.

3. Lawn JE, Blencowe H, Waiswa P, Amouzou A, Mathers C, Hogan D, et al. Stillbirths: rates, risk factors, and acceleration towards 2030. Lancet. 2016;387:587-603.

4. UNICEF. The State of The World's Children 2008. Available from: http://www.unicef.org/sowc08/docs/ sowc08.pdf. Accessed April 22, 2019.

5. Wyckoff MH, Aziz K, Escobedo MB, Kapadia VS, Kattwinkel J, Perlman JM, et al. Part 13: Neonatal Resuscitation: 2015 American Heart Association Guidelines Update for Cardiopulmonary Resuscitation and Emergency Cardiovascular Care. Circulation. 2015;132:S543-60.

6. American Academy of Pediatrics. Helping Babies Breathe. Available from: https://www.aap.org/en-us/advocacy-andpolicy/aap-health-initiatives/helping-babies-survivel Pages/Helping-Babies-Breathe.aspx. Accessed April 22, 2019.

7. Indian Academy of Pediatrics. Newborn Resuscitation
Program: First Golden Minute Project. Available from: http://iapnrpfgm.org/cms/NRP-FGM-Project.php. Accessed April 22, 2019.

8. Bang A, Patel A, Bellad R, Gisore P, Goudar SS, Esamai F, et al. Helping Babies Breathe (HBB) training: What happens to knowledge and skills over time? BMC Pregnancy Childbirth. 2016;16:364.

9. Carlo WA, Goudar SS, Jehan I, Chomba E, Tshefu A, Garces A, et al. Newborn care training and perinatal mortality in developing countries. $N$ Engl $\mathrm{J}$ Med. 2010;362:614-23.

10. Bang AT, Bang RA, Baitule SB, Reddy HM, Deshmukh MD. Management of birth asphyxia in home deliveries in rural Gadchiroli: the effect of two types of birth attendants and of resuscitation with mouth-to-mouth, tube-mask or bag-mask. J Perinatol. 2005;25(Suppl 1):S82-91.

11. Carlo WA, McClure EM, Chomba E, Chakraborty H, Hartwell T, Harris $\mathrm{H}$, et al. Newborn care training of midwives and neonatal and perinatal mortality rates in a developing country. Pediatrics. 2010;126:e1064-71.

12. Bellad RM, Bang A, Carlo WA, McClure EM, Meleth S, Goco N, et al. A pre-post study of a multi-country scale up of resuscitation training of facility birth attendants: does Helping Babies Breathe training save lives? BMC Pregnancy Childbirth. 2016;16:222.

13. Patel A, Khatib MN, Kurhe K, Bhargava S, Bang A. Impact of neonatal resuscitation trainings on neonatal and perinatal mortality: a systematic review and meta-analysis. BMJ Pediatr Open. 2017;1:e000183.

14. Das MK, Chaudhary C, Kaushal SK, Khanna R, Chatterji S. Impact of neonatal resuscitation capacity building of birth attendants on stillbirth rate at public health facilities in Uttar Pradesh, India. Indian Pediatr. 2019;56:369-73. 